\title{
The Tietz syndrome associated with cardiac malformation: a case report with literature review
}

\author{
Youssef Lakhdar ${ }^{\text {* }}$ (D, Hind Abou El Houda ${ }^{2}$, Houda Mounji ${ }^{1}$, Mehdi Elfakiri ${ }^{1}$, Youssef Rochdi ${ }^{1}$, \\ Abdeljalil Moutaouakil ${ }^{2}$ and Abdelaziz Raji ${ }^{1}$
}

\begin{abstract}
Background: Tietz syndrome is a very rare clinical entity characterized by the association of profound bilateral congenital sensorineural deafness and generalized hypopigmentation of skin, eyes, and integuments (snow white appearance). It is an autosomal dominant syndrome due to a mutation in the melanocyte inducing transcription factor (MITF) gene. The association of a heart malformation has never been reported in this syndrome.

Case presentation: We report two cases of two cousins aged 5 years and 20 months respectively with a history of first degree consanguineous parents. Both girls presented with diffuse hypopigmentation of the skin, blond hair, blue eyes, and bilateral diffuse retinal hypopigmentation at ocular fundus exam. Bilateral profound sensorineural hearing loss was confirmed by auditory brainstem response in both cases. Echocardiography revealed a cardiac malformation such as interventricular communication in the older cousin and interatrial communication in the younger cousin. The family investigation did not reveal a similar case among ancestors. The diagnosis of Tietz syndrome was based on clinical criteria and pedigree. The older cousin underwent a total optical correction and a right unilateral cochlear implantation followed by speech therapy with a satisfactory result after a follow-up of two years. Unfortunately, the little cousin died following a head trauma.

Conclusions: Tietz syndrome is a rare autosomal dominant genetic disorder, characterized by generalized albinism with bilateral profound hearing loss. It results from a nontruncating mutation in the basic domain of in the MITF gene. Its management must include, in addition to hearing and ophthalmic rehabilitation, the research and treatment of cardiac malformations which may be life-threatening.
\end{abstract}

Keywords: Tietz syndrome, Albinism, MITF gene, Case report

\section{Background}

The albinism deafness syndrome or Tietz syndrome is a rare genetic disease characterized by the association of a bilateral congenital sensorineural hearing loss and a generalized hypopigmentation of the eyes, skin, and hair. It is an autosomal dominant syndrome due to a mutation in the melanocyte inducing transcription factor (MITF)

\footnotetext{
*Correspondence: lakhdar.orl@gmail.com

${ }^{1}$ ENT and Head and Neck Surgery Department, Mohammed VI University Hospital Center, Marrakech, Morocco

Full list of author information is available at the end of the article
}

gene which controls melanin biosynthesis in the melanocytes and contributes to the color of hair, eyes, and skin. The melanocytes are found in the inner ear where it plays an important role in hearing and MITF gene mutation contributes to bilateral sensorineural hearing loss $[1,2]$. The presence of melanocytes in the heart has been proven in mice and the expression of MITF in the heart is also high [3]. Probably, MITF has a role in cardiac development and hypertrophy, but the real activity in the heart is still unclear [3]. Only few familial cases of Tietz syndrome have been reported in the literature, with some 
cases of sudden death. But heart disease had never been described as a criterion in Tietz syndrome.

\section{Case presentation}

S.A, the proband IV-1 (Fig. 1), was a 5-year-old girl, the only child of a first degree consanguineous couple of Moroccan parents, with no pathological history. Her parents consulted us because of her deafness and dumbness evolving since birth. The dermatological examination showed general hypopigmentation of skin, eyelashes, eyebrows, eyes, and white-yellowish hair. The child was milky-white giving a "snow white" appearance (Fig. 2). According to the parents' report, there was no increase in the level of pigmentation in the skin or hair.

General and cranio-facial clinical examination did not find any malformation or facial dysmorphism. The ophthalmologic examination revealed good visual behavior with hyperopia at +4.75 diopter (D) in the right eye and $+4.00 \mathrm{D}$ in the left eye. The anterior segment's examination showed a cornea of normal size, local hypopigmentation of the iris (Fig. 3), and transparent lens. The pupillary red reflex was present. At the ocular fundus exam, she presented with bilateral diffuse retinal hypopigmentation and a normal macular profile (Fig. 4). Audiological evaluation by puretone and speech audiometry, auditory brainstem response (ABR), and auditory steadystate responses (ASSR) confirmed a congenital profound

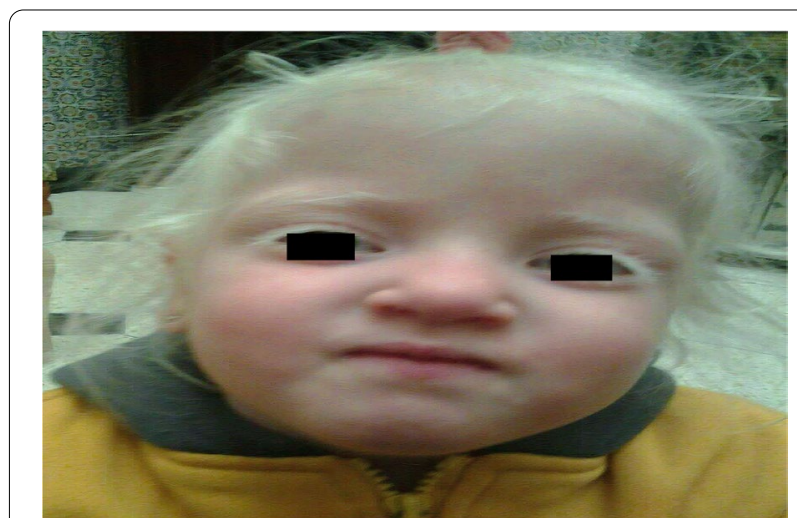

Fig. 2 The girl's image (proband IV-1) showing generalized skin hypo-pigmentation with blond hair, eyelashes, and eyebrows giving the "snow white" appearance

sensorineural deafness. The clinical neurological examination was normal. Computed tomography (CT) and magnetic resonance imaging (MRI) of the central and peripheral auditory pathway did not show any abnormalities or malformations. Electrocardiogram was normal and the echocardiography showed an inter-ventricular communication (IVC) without cardio-dynamic impacts.

The family investigation did not reveal a similar case in the ancestors (Fig. 1). However, a maternal cousin

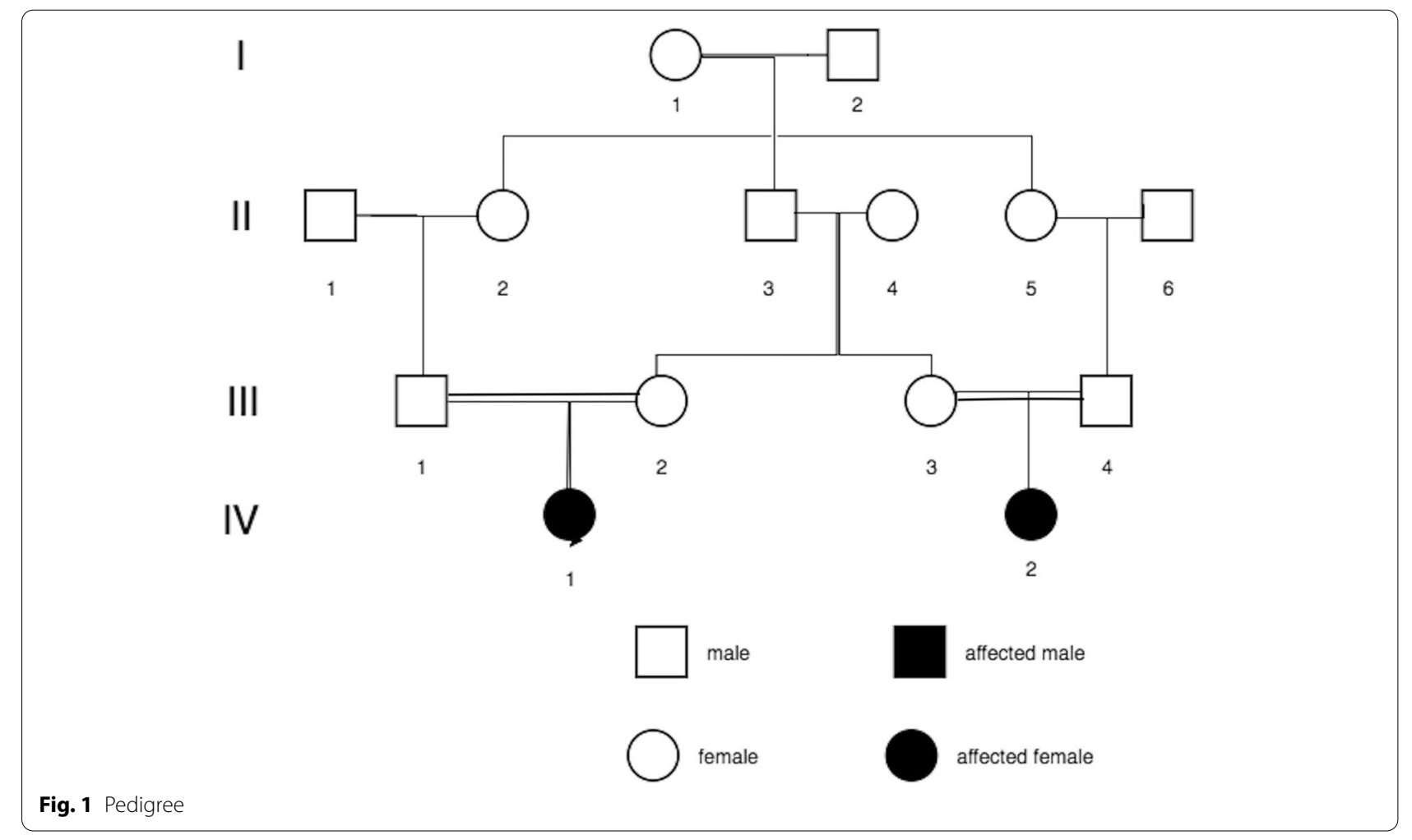




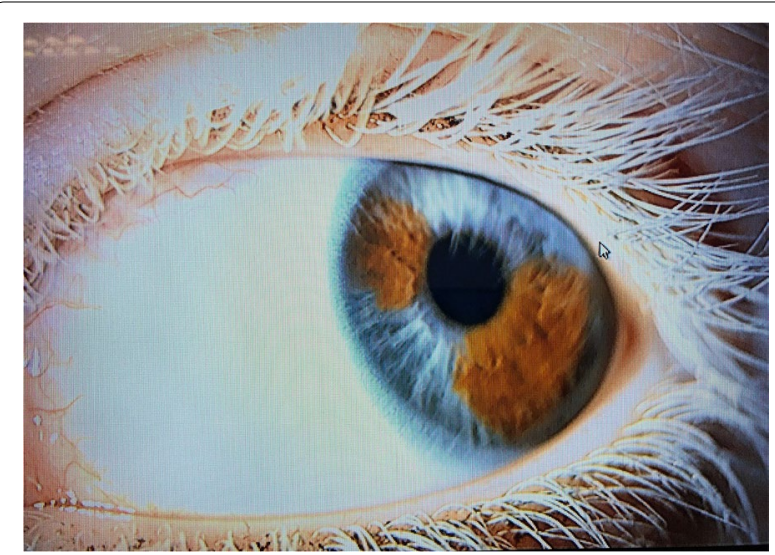

Fig. 3 The girl's image (proband IV-1) which shows local iris hypo-pigmentation

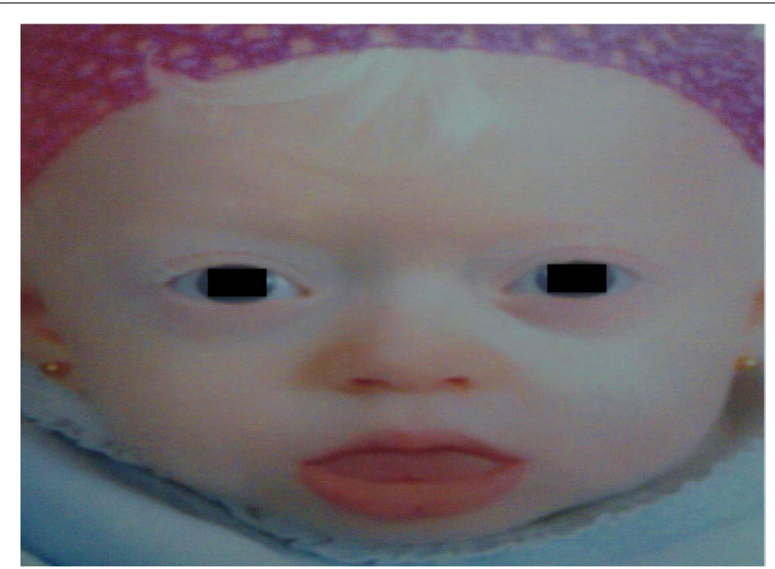

Fig. 5 The girl's image (proband IV-2) showing generalized albinism giving the "snow white" appearance (proband IV-2) had some similar phenotypic characteristics. K. A (proband IV-2) was a 20-month-old girl, with a history of premature birth and consanguineous parents. She showed a similar occulo-cutaneous albinism (Fig. 5) as her cousin (proband IV-1) with hypertelorism, blue irises, and bilateral diffuse retinal hypopigmentation at ocular fundus exam. Behavioral audiometry according to age, ABR, ASSR, and otoacoustic emissions test confirmed the bilateral profound sensorineural hearing loss. Neurologic examination showed generalized axial and peripheral hypotonia. The cardiac examination with echocardiography revealed mitral insufficiency and an inter-auricular communication (IAC) without cardio-dynamic impacts.

The diagnosis of Tietz syndrome was based on clinical criteria and pedigree. The genetic study could not be carried out given the unavailability of research for MITF gene mutations in our country and the parents

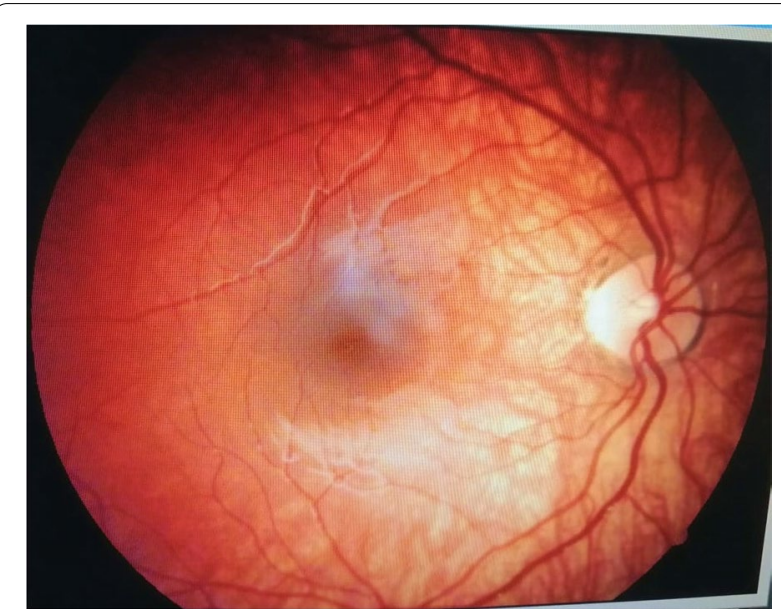

Fig. 4 Fundus image of the girl (proband IV-1) showing bilateral diffuse retinal hypopigmentation and a normal macular profile did not have the financial means to carry out this study abroad.

S.A underwent a total optical correction by eyeglasses and a right unilateral cochlear implantation followed by prolonged speech therapy. The heart defect required only clinical and ultrasound follow-up. After 2 years of follow-up, the child developed an oral language limited to words, allowing her to join a normal primary school. Writing and recognition of images were also improved by optical correction. Child K. A died at the age of 21 months after falling from the bed causing her a head trauma with intracranial hematoma.

Family genetic counseling focused on avoiding subsequent pregnancy for the parents of the cases we described and avoiding consanguineous marriages in this family due to the dominant character of the genetic transmission of this syndrome.

\section{Discussion}

In 1963, Tietz defined the albinism-deafness syndrome as a genetic disease characterized by sensorineural deafness and partial albinism [4]. In 2000, Smith et al. [5] reassessed the same family studied by Tietz, and they confirmed that this syndrome extended over 4 generations, and they added to the description of Tietz syndrome, ocular albinism characterized hypopigmentation of the iris and retina.

Morphologically, patients with Tietz syndrome are milky-white (snow white appearance), fair-skinned with blond hair, eyebrows, and eyelashes [4-6]. But gradually, the skin acquires a semblance of pigmentation on the areas which are exposed to the sun like freckles [4-6]. The irises are blue without nystagmus [5, 6]. The fundus of the patients is striking with a lack of retinal pigmentation and enlarged and irregular papillae $[5,6]$. There are 
no craniofacial anomalies and no telecanthus [4-6]. Sensorineural hearing loss is always bilateral, congenital, and profound [4-6].

Izumi et al. [7] described a young girl with all criteria of Tietz syndrome in whom Histological examination of a skin biopsy revealed the presence of melanocytes, suggesting that the migration of melanocyte stem cells from the neural crest towards the epidermis has taken place. In the hypopigmented regions, there was a reduction in the number of melanosomes in the keratinocytes adjacent to the melanocytes, suggesting an interruption in the transfer of melanosomes from the melanocytes to the keratinocytes.

The typical inherited pattern of Tietz syndrome is autosomal dominant $[1,4-6]$. At the chromosome level this syndrome is associated with a nontruncating mutation in the basic domain of melanocyte inducing transcription factor (MITF) gene $[1,8]$. The human MITF is located on chromosome 3p13, and it consists of 10 exons, spanning approximately 22.8 kilobases $(\mathrm{kb})$ [1]. This gene enables the synthesis of a protein called melanocyte inducing transcription factor (MITF) which helps control the development and function of melanocytes $[1,2,8]$. The production of melanin in melanocytes contributes to the color of hair, eyes, and skin. Also, the melanocytes are found in the inner ear and play an important role in hearing $[1,2]$, but the precise function of cochlear melanocytes in the stria vascularis remains uncertain, probably facilitating directly or indirectly $\mathrm{K}+$ transport in endolymph [2]. The MITF protein regulates the development of specialized cells in the eye called retinal pigment epithelial cells that nourish the retina [2].

Ichiro Y [9] found that, in the mice, melanocytes were localized in the valves (mitral, tricuspid, and aortic) and septa (ventricular and atrial); in this study, mice presenting skin hyper or hypo-pigmentation show an increase or decrease in heart pigmentation. But the real role of melanocytes in the heart remains unclear. The MITF gene has also a role as a transcription factor in heart muscle [10]. According to Tshori et al. [3] and Hodgkinson et al. [11], MITF is highly expressed in the heart, and it is an essential regulator of cardiac growth and hypertrophy. As in our two clinical cases, we believe that the relationship between the mutation of the MITF gene and the congenital defects of the cardiac septum (IAC or IVC) is possible. Mice with mutations in heart-specific isoform of MITF (MITF-H) had reduced hypertrophic response to beta-adrenergic stimulation [3]. They also had reduced levels of brain natriuretic peptide (BNP), a critical modulator of cardiac hypertrophy [3]. MITF-H directly regulates the expression levels of MLC-1a, a motor protein in the heart [3], and negatively regulates the expression levels of miR-541 that inhibits cardiac hypertrophy induced by angiotensin II [12]. MITF is also reported to be decreased in heart failure patient samples [13]. Tshori S et al. [3] found that MITFmutated mice had greatly decreased heart weight/body weight ratio, systolic function, and cardiac output, with a tendency to sudden death following $\beta$-adremainsrenergic stimulation. Despite a considerable role in cardiac development and hypertrophy, little is known about how the activity of this heart-specific isoform of MITF is regulated.

About 70 mutations of MITF have been reported in patients with Tietz/Waardenburg type 2 syndrome, especially the mutation p.Arg217Ile and p.Arg217Gly [4]. Tassabehji et al. [14] and Izumi et al. [7] have already identified a $3 p$ deletion of the MITF gene (delR217). The MITF mutations most commonly lead to Waardenburg syndrome type 2A (WS2A), characterized by varying degrees of sensorineural hearing loss and an uneven regional distribution of skin hypopigmentation, including heterochromia of the iris and white forelock [15]. On rare occasions, mutations in the MITF gene lead to Tietz syndrome (TS), which is distinguished from WS2 by generalized rather than patchy hypopigmentation and complete hearing loss [15].

According to our review of the literature, heart malformation has not been described as diagnostic criteria in Tietz syndrome or Waardenburg syndrome. But Ziprkowski and Adam [16] described a Moroccan Jewish family of 6 generations in which two children in each of two sibships born from consanguineous parents had congenital deafness with total albinism; In this family, the lifespan was rather short, with undiagnosed heart disease as the main cause of death. The two cases that we describe presented a cardiac defect type IAC and IVC discovered on echocardiography.

In Tietz syndrome, cardiac malformations can be probably linked either to the mutation of the MITF gene but this hypothesis has never been explored [3] or linked to other associated genetic abnormalities that might be favored by consanguinity.

\section{Conclusions}

Tietz syndrome is a rare, genetic autosomal dominant disorder characterized by generalized cutaneous and ocular albinism associated with bilateral profound hearing loss. Its management care multidisciplinary approach including pediatrician, cardiologist, ophthalmologist, and otologist. Hearing rehabilitation by cochlear implant must be early allowing acquisition of an oral language. There are reports of unexplained sudden deaths among cases of Tietz syndrome at a relatively young age. The presence of this incidental cardiac anomaly finding raises the recommendation of thorough cardiac assessment in these patients. 


\section{Abbreviations}

MITF: Melanocyte inducing transcription factor; D: Diopter; ABR: Auditory brainstem response; ASSR: Auditory steady-state responses; CT: Computed tomography; MRI: Magnetic resonance imaging; IVC: Inter-ventricular communication; IAC: Inter-auricular communication; TS: Tietz syndrome; WS2A: Waardenburg syndrome type 2A; BNP: Brain natriuretic peptide.

\section{Acknowledgements}

Not applicable.

\section{Authors' contributions}

All authors have read and approved the manuscript. $Y L, H A, A R$, and $A M$ made the diagnosis. AR and $A M$ treated the child. $Y L, H A$, and $H M$ obtained the consent of the family. $Y L$ and $H A$ wrote the majority of the manuscript and the iconography. ME and HM contributed to the writing of the clinical case and the iconography. AR, AM, and YR critically reviewed the manuscript.

\section{Funding}

This research did not receive any specific grant from funding agencies in the public, commercial, or not-for-profit sectors.

\section{Availability of data and materials}

Not applicable.

\section{Declarations}

\section{Ethics approval and consent to participate}

Not applicable.

\section{Consent for publication}

The parents of the children mentioned in this article have given informed consent for the publication of the two clinical cases and the images. written consent to publish this information was obtained from the parents of participants.

\section{Competing interests}

All authors declare that they have no competing interests.

\section{Author details}

${ }^{1}$ ENT and Head and Neck Surgery Department, Mohammed VI University Hospital Center, Marrakech, Morocco. ${ }^{2}$ Ophthalmology Department, Mohammed VI University Hospital Center, Marrakech, Morocco.

Received: 6 July 2021 Accepted: 11 October 2021

Published online: 09 November 2021

\section{References}

1. Yu R, Liu L, Li Y-L, Fan L-L (2021) MITF p.Arg217Thr variant identified in a Han Chinese family with Tietz/Waardenburg syndrome. BioMed Res Int Article ID 4381272:6. https://doi.org/10.1155/2021/4381272

2. Roydon EP, David EF (2001) Sensorineural deafness minireview and pigmentation genes: melanocytes and the Mitf Transcriptional Network. Neuron 30:15-18. https://doi.org/10.1016/S0896-6273(01)00259-8
3. Tshori S, Gilon D, Beeri R, Nechushtan H, Kaluzhny D, Pikarsky E, Razin E (2006) Transcription factor MITF regulates cardiac growth and hypertrophy. J Clin Invest 116(10):2673-2681. https://doi.org/10.1172/JCI27643

4. Tietz W (1963) A syndrome of deaf-mutism associated with albinism showing dominant autosomal inheritance. Am J Hum Genet 15(3):259_ 264 PMCID: PMC1932384. PMID: 13985019

5. Smith SD (2000) Tietz syndrome (hypopigmentation/deafness) caused by mutation of MITF. J Med Genet 37(6):446-448

6. Amiel J, Watkin PM, Tassabehji M, Read AP, Winter RM (1998) Mutation of the MITF gene in albinism-deafness syndrome (Tietz syndrome). Clin Dysmorphol 7(1):17-20

7. Izumi K, Kohta T, Kimura Y, Ishida S, Takahashi T, Ishiko A et al (2008) Tietz syndrome: unique phenotype specific to mutations of MITF nuclear localization signal. Clin Genet 74(1):93-95

8. Léger S, Balguerie X, Goldenberg A, Drouin-Garraud V, Cabot A, AmstutzMontadert I et al (2012) Novel and recurrent non-truncating mutations of the MITF basic domain: genotypic and phenotypic variations in Waardenburg and Tietz syndromes. Eur J Hum Genet 20(5):584-587

9. Ichiro $Y$, Lionel $L$ (2008) The location of heart melanocytes is specified and the level of pigmentation in the heart may correlate with coat color. Pigment Cell Melanoma Res 21:471-476. https://doi.org/10.1111/j.1755148X.2008.00483.X

10. Grépin C, Durocher D, Nemer M (1995) Le cœur : un programme unique de transcription et de différenciation musculaire. Médecine/Sciences 11(3):395

11. Hodgkinson CA, Karen JM, Nakayama A, Steingrímsson E, Copeland NG, Jenkins NA, Arnheiter H (1993) Mutations at the mouse microphthalmia locus are associated with defects in a gene encoding a novel basic-helixloop-helix-zipper protein. Cell 74(2):395-404. https://doi.org/10.1016/ 0092-8674(93)90429-T

12. Liu F, Li N, Long B, Fan YY, Liu CY, Zhou OY, Murtaza I, Wang K, Li PF (2014) Cardiac hypertrophy is negatively regulated by miR-541. Cell Death Dis 5:e1171 https://doi.org/10.1038/cddis.2014.141

13. Gao Z, Xu H, DiSilvestre D, Halperin VL, Tunin R, Tian Y, Yu W, Winslow RL, Tomaselli GF (2006) Transcriptomic profiling of the canine tachycardiainduced heart failure model: global comparison to human and murine heart failure. J Mol Cell Cardiol 40(1):76-86. https://doi.org/10.1016/j. yjmcc.2005.08.002

14. Tassabehji M, Newton VE, Liu XZ, Brady A, Donnai D, Krajewska-Walasek $M$ et al (1995) The mutational spectrum in Waardenburg syndrome. Hum Mol Genet. nov 4(11):2131-2137

15. Cortés-González V, Zenteno JC, Guzmán-Sánchez M, Giordano-Herrera V, Guadarrama-Vallejo D, Ruíz-Quintero N et al (2016) Tietz/Waardenburg type 2A syndrome associated with posterior microphthalmos in two unrelated patients with novel MITF gene mutations. Am J Med Genet A déc 170(12):3294-3297

16. Ziprkowski L (1962) Partial albinism and deaf mutism: due to a recessive sex-linked gene. Arch Dermatol 86(4):530

\section{Publisher's Note}

Springer Nature remains neutral with regard to jurisdictional claims in published maps and institutional affiliations. 